\title{
Evolutionary Game Analysis of Firms' Technological Strategic Choices: A Perspective of the Behavioral Biases
}

\author{
Yingqing Zhang $\left(\mathbb{D},{ }^{1,2}\right.$ Ruguo Fan $\mathbb{D D}^{3}{ }^{3}$ Ming Luo $\mathbb{D}^{2},{ }^{2}$ Mingman Chen $\mathbb{D}^{1},{ }^{1}$ and Jiaqin Sun $\mathbb{D i D}^{3}$ \\ ${ }^{1}$ School of Management Science and Engineering, Guizhou University of Finance and Economics, Guiyang 550025, China \\ ${ }^{2}$ Economics and Management School, Guangxi Normal University, Guilin 541000, China \\ ${ }^{3}$ Economics and Management School, Wuhan University, Wuhan 430072, China
}

Correspondence should be addressed to Ming Luo; luoming831@163.com

Received 7 July 2020; Revised 21 January 2021; Accepted 23 January 2021; Published 4 February 2021

Academic Editor: Yi Su

Copyright (c) 2021 Yingqing Zhang et al. This is an open access article distributed under the Creative Commons Attribution License, which permits unrestricted use, distribution, and reproduction in any medium, provided the original work is properly cited.

\begin{abstract}
To reveal the mechanisms of firms' technological strategic choices between innovation and imitation, an evolutionary game model is proposed from the perspective of the behavioral biases. First, behavioral biases such as reference point dependence, loss aversion, and probability weighting can be defined and modeled based on the prospect theory. Second, according to the firm theory, a Cournot or Stackelberg game modeled with a technology spillover effect and intellectual property protection is applied to portray the interaction between firms. Third, an improved evolutionary game model is provided by incorporating behavioral biases into the framework of the decision-making process. Finally, the simulation analysis of some important factors, such as intellectual property protection, patent fees, innovation risks, decision-making attitudes, and consumers' price preference on firms' technological strategic choices, is presented. The corresponding results show that (1) innovation risk is an important factor affecting the technological strategic choices of firms, (2) increasing the intellectual property protection and the patent fee for technology transfer can effectively control the spillover effect of technology, (3) there is a partial U-shaped relationship between the consumers' price preference and innovation, and (4) the behavioral biases such as reference point dependence, loss aversion, and probability weighting will change the perception of payoff and risk and will eventually induce firms to adopt the innovation strategy.
\end{abstract}

\section{Introduction}

Firms' technological strategic choice in the market is complex and dynamic. First, after entering the market, firms will often face the choice of binary strategies, i.e., whether to choose incremental innovation strategy or radical innovation strategy, sustaining innovation strategy or disruptive innovation strategy, imitation innovation strategy or original innovation strategy, close innovation strategy or open innovation strategy, substantive innovation or strategic innovation, etc [1]. Each strategy is closely linked with the competitive environment, market structure, and innovation ability [2-4]. Second, firms will still face the problem of acting first or acting later in terms of investing in R\&D (Research and Development). The first mover may become a technology leader and gain a large market share but at the same time also face high R\&D costs and higher innovation risks, while the later entrants may avoid the corresponding risks and obtain new business benefits through technological upgrading [5]. Third, the strategic choice is an interactive dynamic process. Firms will continue to adjust their strategic choices based on previous returns and competitors' strategic choices [6].

Firms' strategic choices can be roughly divided into two types: innovation and imitation. (1) Innovation is an influential factor for firm survival and growth [7]. On the one hand, innovation can help a firm to build strong barriers and be the first to bring a brand-new technology to market and gain a large market share. On the other hand, a firm with an innovation strategy can achieve leapfrog development and form core competitiveness through continuous technological development. In particular, innovation can be divided 
into process innovation and product innovation [8, 9]. Process innovation is defined as a reduction in a firm's marginal costs (i.e., cost-reducing R\&D innovation), while product innovation is interpreted as an improvement in the quality of the product (i.e., quality-improving R\&D innovation). Zhou et al. established a dynamic two-stage Cournot duopoly game with an R\&D spillover effect and noted that $R \& D$ is a creative activity of firms that increases their knowledge and further reduces their production costs [10]. Takashima and Ouchida considered a quality-improving R\&D and merger policy in a differentiated duopoly and found that a merger can better encourage $\mathrm{R} \& \mathrm{D}$ investment than the R\&D competition [11]. In addition, Sun analyzed both the cost-reducing $\mathrm{R} \& \mathrm{D}$ and quality-improving $\mathrm{R} \& \mathrm{D}$ activities in a Hotelling model with an endogenous spillover effect and noted that these two R\&D activities will have the same strategic properties and that the equilibrium strategy of the quality-improving $\mathrm{R} \& \mathrm{D}$ model can be derived from the cost-reducing $\mathrm{R} \& \mathrm{D}$ model [12]. It can be seen that process innovation affects marginal production costs, while product innovation affects product prices. (2) Imitation is a strategy that prefers the intentional copying of the innovator's existing technology, design, and business models as well as organizational practices [13]. The concept of imitation is the extent related to the concept of late entrants, and the imitators can seem as the followers with the passive suitability. Under an imitation strategy, imitators can reduce R\&D costs through spillover from the innovators, but it is difficult to formulate long-term technology accumulation in the process of technology development. However, according to Golder and Tellis [14], the failure rates of innovators and imitators are $47 \%$ and $8 \%$, respectively. Imitators can exploit the innovators' efforts to develop the technology or products and as late entrants can even overtake pioneers in various markets. To date, the role of innovation and imitation strategies is widely recognized, such as they can both improve the firm productivity, but there is still no consensus on which is better.

According to the recent studies, whether firms choose innovation or imitation is related not only to external factors, such as innovation risks, intellectual property protection, and technology spillover, but also to the behavioral biases of decision makers, such as reference point dependence, loss aversion, and probability weighting $[15,16]$. For example, the innovative, strategic, and risk-taking traits of CEOs will positively relate to entrepreneurship and can improve firm performance [17]. Some scholars further consider that firms are no longer considered simple actors with a stress-response style but rather as agents with perception, interest trade-offs, and complex decision-making ability $[18,19]$. For example, reference point dependence is an important benchmark for the firm to judge whether a strategy will eventually bring gains or losses [20], which indicates that firms may pay more attention to the change in wealth than to the final level of wealth in the process of decision making [21]. In addition, loss aversion describes the situation that firms or investors will tend to continue to hold a loss or assets in anticipation of a rebound phenomenon when suffering a loss or asset depreciation [22, 23]. It can be seen that behavioral biases will greatly affect the process of strategic choices.

Hence, this article continues with this line of thought and mainly investigates the following research questions. (1) What are the behavioral biases of firm decision makers? (2) How can behavioral biases be modeled into the process of decision making? (3) How do behavioral biases influence the firms' technological strategic choices between innovation and imitation?

Analyzing the relationship between behavioral biases and strategic choices at the firm's behavior level presents two challenges. First, it is necessary to properly define and model behavioral biases, such as reference point dependence, loss aversion, and probability weighting. Second, behavioral biases should be incorporated into the interactive process among firms. Therefore, to address the above challenges, this article fuses prospect theory and evolutionary game theory to reveal the influence of behavioral biases on strategic choices.

The main contributions of this paper can be summarized as follows. (1) A new evolutionary game model based on prospect theory is proposed, which comprises behavioral biases such as reference point dependence, loss aversion, and probability weighting. (2) In terms of the sequence of actions for innovation and imitation, a Cournot or Stackelberg game model with technology spillover effects and intellectual property protection is applied to portray the competition between firms. (3) The mechanisms of behavioral biases on the firms' technological strategic choices are revealed based on the prospect theory.

The remainder of this paper is organized as follows. In Section 2, we conduct a literature review on the behavioral biases. Section 3 presents a basic evolutionary game model and an improved evolutionary game model based on prospect theory. In Section 4, the simulation analysis and the results are presented. Finally, the conclusions and discussions are discussed in Section 5.

\section{Literature Review}

In addition to focusing on the impact of intellectual property protection, patent fees, and other factors on innovation decisions [24], we follow the studies that explain firms' different systematic behavioral biases from the perspective of cognition. Early studies analyzed behavioral biases from the perspectives of bounded rationality, farming, inconsistent risk aversion, certain effects, etc [25]. It is difficult to form a unified analysis framework based on these theories. It is worth mentioning that prospect theory may provide an analytical framework comprising the following elements to capture the behavioral biases [26, 27]:

(1) Reference Point Dependence. The reference point plays a critical role in the decision-making process. Decision makers care about the final returns as well as the changes in returns concerning a reference point [28]. That is to say, the reference point determines how firms frame the returns of a strategy. A large number of studies have confirmed this 
conclusion. For example, Greve found evidence from shipbuilding that the R\&D intensity is related to the distance between the performance and aspiration level and pointed out that the high performance will reduce $R \& D$ intensity, while performance below aspiration level will increase R\&D intensity [29]. Accordingly, they perceive a given return as a gain (loss) when above (below) the reference point. This shows that the core issue here is the selection of the reference point because the same outcome may be evaluated differently under different reference points. Most researchers measured a common reference point by the industry median or mean of returns. Wiseman and Catanach used average performance as the reference point and found that below-average firm performance will create a loss frame and stimulate risk-seeking behavior [30]. Additionally, Short and Palmer argued that firms use many reference points and that they may change over time [31].

(2) Loss Aversion. According to classical economic theory, the basic assumption of risk return is a positive relationship. However, much evidence shows that when returns are below their expectations, decision makers in firms may perceive greater dissatisfaction than satisfaction when returns exceed their expectations [32-34]. A typical example is the endowment effect experiment, in which decision makers are more simulated to changes that are considered as losses than equal-sized changes that are regarded as gains. This phenomenon is called Bowman's paradoxical negative risk return or loss aversion [35]. Some scholars consider it a paradox of human cognition that while people are risk-averse, they also tend to be optimistic [36]. In particular, the strategic choice behavior will be risk-averse when firms perceive gains and risk-seeking when perceiving losses. In the empirical studies, Kliger and Tsur examined the relationship between the returns and risk level by using the COMPUSTAT data and showed that firms with returns above their expectations will assume less risk than those firms with returns below their expectations [37]. Situmeang et al., in a study of 362 game developer firms, further found that a stable market will negatively influence new market entry while a high-degree variable market will positively influence new market entry [38]. This conclusion is also supported by a study that examined the 379 firms in India [35].

(3) Probability Weighting. Probability weighting is the decision maker's perception of the probability of an event, which is traditionally considered as a linear function. However, an abundance of evidence shows that the individuals do not use objective probabilities to evaluate the possibility of an event but rather the transformed probabilities obtained from objective probabilities via mental processing [39-41]. A recent empirical study by Stearns shows that innovation will may fail fast as a result of overconfidence by a firm's managers, which indicates that the cognitive biases may affect investment decisions [42]. The most important feature of the probability weighting is that low probabilities are overweighted and high probabilities are underestimated [43]. That is, decision makers more accurately simulate the probability of rare events than typical events. Many mechanisms have been proposed to explain probability weighting, such as anchoring bias [44], probability estimation error [45], and salience-based theory [46]. In the financial markets, probability weighting is applied to explain the underdiversification of household portfolios [47], stock prices, and asset prices [48-50]. For example, probability weighting may matter in merger and acquisition deals. The reason for this is that investors may overestimate the true probability of deal failure, which results in a lower willingness to pay for deals with small failure probabilities.

The above studies suggest that the behavioral biases of the decision maker will affect the decision-making behavior to a certain extent. However, previous studies have paid less attention to the firms' technological strategic choices; most of these studies use only one or two elements of prospect theory, and few studies treat it as a coherent whole. Therefore, to reveal the influence of behavioral biases on strategic choices, behavior with prospect theory is applied. First, behavioral biases such as reference point dependence, loss aversion, and probability weighting can be defined and modeled based on the prospect theory. Second, according to the firm theory, a Cournot or Stackelberg game model with a technology spillover effect and intellectual property protection is applied to portray the interaction between firms. A Cournot game is mainly used to describe the competition situation when two firms adopt the same strategy (imitation or innovation) simultaneously. A Stackelberg game portrays the orderly competition with one firm as the first mover to adopt an innovation strategy and another firm as a later entrant to adopt an imitation strategy. Third, an improved evolutionary game model is provided by incorporating behavioral biases into the framework of the decision-making process. Therein, it mainly uses the perception payoff formed by the value function to replace the final payoff formed by the utility function and replaces the objective probabilities with the transformed probabilities. Finally, the simulation analysis of some important factors, such as intellectual property protection, patent fees, innovation risks, decisionmaking attitudes, and consumers' price preference for strategic choices, is presented.

\section{The Model}

\subsection{Assumptions}

Assumption 1. To simplify the problem, this article assumes that there are two alternative strategic choices, namely, innovation strategy $(C)$ and imitation strategy $(M)$, that can be adopted by each firm to compete in the market, and each 
firm will make optimal production decisions to maximize profits [51-53]. Firms that adopt innovation strategies are called the innovation-leading firms, while those that adopt imitation strategies are called the imitation-following firms. In terms of the innovation-leading firms, intellectual property protection is a very important way to protect their vested interests by curbing technology spillover. Imitationfollowing firms can achieve innovative technology by paying a certain patent fees to the innovation-leading firms.

Assumption 2. In general, when the innovation-leading firms increase the intellectual property protection, other imitation-following firms have difficulty free riding on innovative technology by technology spillover [6]. The stronger the intensity of property protection, the greater extent to which the technology spillover effect will be contained. Here, we assume that there is a negative correlation between intellectual property protection and technology spillover [54-56]. The specific relationship is set as follows:

$$
\theta=1-\beta
$$

where $\theta$ represents the extent of intellectual property protection, $\theta \in[0,1]$, and $\beta$ denotes the technology spillover, $\beta \in[0,1]$, in which $\beta=0$ indicates that there are no spillovers and $\beta=1$ means that the firm can obtain the same technology as a rival.

Assumption 3. A constant marginal cost $A$ can be reduced by investing in $\mathrm{R} \& \mathrm{D}$. The $\mathrm{R} \& \mathrm{D}$ investment allows a firm to reduce its marginal cost $A$ by the amount $s$, where $s \in[0,1]$, and $s$ can also be regarded as the R\&D investment level. In addition, due to the technology spillover effect, the marginal cost of a firm is still reduced by the rival's R\&D outcomes. However, subject to intellectual property protection, the unit cost reduction for firm $i$ is $(1-\theta) s_{j}$. The total cost of production generally includes unit marginal cost and fixed $R \& D$ cost [57], namely,

$$
C_{i}\left(q_{i}, R, \theta\right)=\left[A-H(w) s_{i}-(1-\theta) H(w) s_{j}\right] q_{i}+H(w) R_{i},
$$

where $H(w)$ is the indicator function. $H(w)=1$ stands for the firm's decision to engage in $\mathrm{R} \& \mathrm{D}$ and $H(w)=0$ means that the firm abstains from innovation. $R_{i}$ is the fixed R\&D cost.

The R\&D cost is assumed to be quadratic, which reflects the diminishing returns to levels of R\&D efforts [58, 59]. The relationship is shown as follows:

$$
R_{i}=\frac{\gamma s_{i}^{2}}{2}
$$

where $\gamma$ represents the $\mathrm{R} \& \mathrm{D}$ cost coefficient. Therefore, the total marginal cost of the firm can be rewritten as follows:

$$
C_{i}\left(q_{i}, R, \theta\right)=\left[A-H(w) s_{i}-(1-\theta) H(w) s_{j}\right] q_{i}+H(w) \frac{\gamma s_{i}^{2}}{2}
$$

Assumption 4. The linear inverse demand function has been widely adopted in the research concerning oligopolistic competition [60], which can be described as follows:

$$
p_{i}=a-q_{i}-q_{j}
$$

where $p_{i}$ is the price, $a$ is the market potential capacity, and $q_{i}$ and $q_{j}$ represent the quantity of firm $i$ and quantity of firm $j$, respectively.

Furthermore, evidence indicates that R\&D investment cannot only reduce the cost of production of the product but also improve the quality of the product, thereby affecting the product's price $[61,62]$. Holcombe argues that quality is implicit in product differentiation, and the differentiated products may result in different prices [63]. It can be seen that R\&D investment achieves product differentiation through improved production technologies, thereby affecting the market equilibrium price. Specifically, firms that choose an innovation strategy will obtain high-quality differentiated products through R\&D investment, and the improvement of quality is reflected in consumers' price preferences for products. Therefore, to reflect the consumer's price preference for differentiated products, this article introduces a parameter $\varphi$, so the product price of the firms that choose the innovation strategy is

$$
p_{i, c}=a-q_{i}-\varphi q_{j}
$$

For firms that choose the imitation strategy, because they have not invested in $\mathrm{R} \& \mathrm{D}$, consumers' price for this product will decrease. At this time, the price is

$$
p_{i, M}=\varphi\left(a-q_{i}-q_{j}\right)
$$

where $\varphi$ measures the price preference between the differentiated products and $\varphi \in(0,1]$. When $\varphi$ is set as 1 , there is no difference in consumers' price preference between innovation products and imitation products. While $0<\varphi<1$, it shows that consumers have a price preference, and the smaller the value $\varphi$, the greater the difference between imitation products and innovative products for consumers' price preference. And $p_{i, C}, p_{i, M}$, and $p_{i, M}$ satisfy $p_{i, M}<p_{i}<p_{i, M}$. That is, consumers pay more for innovation products than for the imitation products.

3.2. The Basic Evolutionary Game Model. The market competition between two firms can seem like a typical game process [64], which could be composed of four stages. (1) The first stage is the selection of the strategy. When they both adopt the innovation strategy or the imitation innovation strategy at the same time, they play a Cournot game. When they adopt different strategies, they play a Stackelberg game with an order of action. (2) The second stage is the R\&D investment. A firm that adopts an innovation strategy will determine its optimal R\&D investment level, while a firm that adopts an imitation strategy will not carry out this process. (3) The third stage is production decision making. Firms will make optimal production decisions under the optimal R\&D investment level and optimal prices. (4) The fourth stage is the strategy adjustment. In the process of 
continuous market competition, firms adjust the next strategy according to the previous payoff to obtain higher returns in the future.

The payoff matrix owing to different strategies adopted by firm $i$ and firm $j$ is shown in Table 1 .

Under the different combinations of two strategies chosen by two firms, three market situations will be constructed as follows: (1) when two firms adopt an innovation strategy simultaneously, they carry out a Cournot game [65]; (2) when one firm adopts the innovation strategy and another adopts the imitation strategy, it means that there is an orderly competition in production and they carry out a Stackelberg game [66]; and (3) when two firms adopt an imitation strategy, they carry out a Cournot game without the R\&D investment. The payoffs from the different situations are presented as below.

Situation 1. Firm $i$ and firm $j$ both adopt an innovation strategy.

In this situation, the Cournot game model between two innovation-leading firms is applied to construct the model. During the R\&D investment stage, both firms can share the benefits of technology spillovers and then compete with each other in terms of production. Since both firms choose an innovation strategy at the same time, the price of innovation
TABLE 1: The payoff matrix of the basic evolutionary game model.

\begin{tabular}{cccc}
\hline & \multicolumn{2}{c}{ Firm $j$} \\
& & Innovation & Imitation \\
& strategy $(C)$ & strategy $(M)$ \\
\hline \multirow{2}{*}{ Firm $i$} & Innovation strategy $(C)$ & $\pi_{i, C}^{C}, \pi_{j, C}^{C}$ & $\pi_{i, C}^{S}, \pi_{j, M}^{S}$ \\
& Imitation strategy $(M)$ & $\pi_{i, M}^{S}, \pi_{j, C}^{S}$ & $\pi_{i, M}^{C}, \pi_{j, M}^{C}$ \\
\hline
\end{tabular}

products is $p_{i, C}$. Therefore, the objective of the firm is to choose an innovation strategy that maximizes profits:

$$
\left\{\begin{array}{l}
\max _{q_{i}} \pi_{i, C}^{C}=\left[a-q_{i}-\varphi q_{j}-\left(A-s_{i}-(1-\theta) s_{j}\right)\right] q_{i}-\frac{\gamma s_{i}^{2}}{2}, \\
\max _{q_{j}} \pi_{j, C}^{C}=\left[a-q_{i}-\varphi q_{j}-\left(A-s_{j}-(1-\theta) s_{i}\right)\right] q_{j}-\frac{\gamma s_{j}^{2}}{2} .
\end{array}\right.
$$

The solution concept is the subgame perfect Nash equilibrium, and the game is solved by backward induction. First, firms determine their optimal R\&D investment level $s_{k}^{*}$ according to the best response to production. Second, the optimal equilibrium productions $q_{k}^{*}$ are solved based on the given R\&D investment level $s_{k}^{*}$. Then, firms' profit maximization is derived:

$$
\begin{aligned}
\pi_{k, C}^{C^{*}} & =\left[\frac{(2-\varphi)(a-A)+(4-2 \varphi-2 \theta+\varphi \theta) s_{k}^{*}}{4-\varphi^{2}}\right]-\frac{\gamma}{2} s_{k}^{* 2}, \quad k=i, j, \\
s_{k}^{*} & =\frac{2 L_{1} L_{2}}{\gamma-2 L_{2}^{2}-2 L_{3} L_{2}}, \\
L_{1} & =\frac{a-A}{2+\varphi}, \\
L_{2} & =\frac{2-\varphi+\varphi \theta}{4-\varphi^{2}}, \\
L_{3} & =\frac{2-\varphi-2 \theta}{4-\varphi^{2}} .
\end{aligned}
$$

Situation 2. Firm $i$ adopts an innovation strategy, and firm $j$ adopts an imitation strategy.

In this situation, the strategy selection is in order. The first mover may become an innovation-leading firm while the later entrants may become an imitation-following firm. Therefore, the Stackelberg game with an orderly competition is applied. In general, when the innovation-leading firms increase the intellectual property protection, other imitation-following firms have difficulty free riding on innovative technology by technology spillover, but they can acquire the technology by technology transfer. According to the research of Žigić [67], licensing trade as a simple and easy approach to operate technology transfer is widely used. On the one hand, for the innovation-leading firms, the high innovation investment in the early stage can be quickly recovered through licensing trade, and the innovation risk in the future can be reduced. On the other hand, the imitationfollowing firms can acquire new technology as quickly as possible by paying certain patent fees, which reduces the unit cost of production to a certain extent. In addition, since firm $i$ chooses an innovation strategy and enterprise $j$ chooses an imitation strategy, the product price of firm $i$ and firm $j$ is $p_{i, C}$ and $p_{i, M}$, respectively. Therefore, the firms' profit maximization is transformed into 


$$
\begin{aligned}
& \left\{\begin{array}{l}
\max _{q_{i}} \pi_{i, C}^{S}=\left[a-q_{i}-\varphi q_{j}-\left(A-s_{i}\right)\right] q_{i}-\frac{\gamma s_{i}^{2}}{2}+f, \\
\max _{q_{j}} \pi_{j, M}^{S}=\left[a-q_{j}-\varphi q_{i}-\left(A-(1-\theta) s_{i}\right)\right] q_{j}-f,
\end{array}\right. \\
& f=\rho \pi_{j, M}^{S}=\rho\left[\varphi\left(a-q_{j}-q_{i}\right)-\left(A-(1-\theta) s_{i}\right)\right] q_{j},
\end{aligned}
$$

where $f$ represents the patent fees. The patent fees is the royalty payment based on the total payoff. This article uses $\rho$ as a percentage of the total payoff, which can also be regarded as the bargaining power of the innovation-leading firm [68].

The backward induction method is used to solve the problem [69], and the optimal payoff of the innovationleading firm and the imitation-following firm is shown below:

$$
\begin{aligned}
& \pi_{i, C}^{S *}=\left[a-q_{i}^{*}+\frac{\varphi}{2} q_{i}^{*}-A+s_{i}^{*}-\varphi V\right] q_{i}^{*}-\frac{\gamma}{2} s_{i}^{* 2}+\rho \varphi\left[V-\frac{q_{i}^{*}}{2}\right]^{2}, \\
& \pi_{j, M}^{S *}=(1-\rho) \varphi\left[V-\frac{q_{i}^{*}}{2}\right]^{2} \\
& V=R_{1}+R_{2} s_{i}^{*} \\
& R_{1}=\frac{\varphi a-A}{2 \varphi} \\
& R_{2}=\frac{1-\theta}{2 \varphi} \\
& q_{i}^{*}=M_{1}+M_{2} s_{i}^{*} \text {, } \\
& M_{1}=\frac{2 a-2 A-(1+\rho)(\varphi a-A)}{4-2 \varphi-\rho \varphi}, \\
& M_{2}=\frac{2-(1+\rho)(1-\theta)}{4-2 \varphi-\rho \varphi} \text {, } \\
& s_{i}^{*}=\frac{M_{1}\left[1+((\varphi / 2)-1) M_{2}-\varphi R_{2}\right]+M_{2}\left[a-A+((\varphi / 2)-1) M_{1}-\varphi R_{1}\right]+2 \rho \varphi\left(R_{2}-\left(M_{2} / 2\right)\right)\left(R_{1}-\left(M_{1} / 2\right)\right)}{\gamma-2 M_{2}\left[1+((\varphi / 2)-1) M_{2}-\varphi R_{2}\right]+2 \rho \varphi\left(R_{2}-\left(M_{2} / 2\right)\right)^{2}} . \\
& \pi_{k, M}^{C^{*}}=\pi_{k, M}^{C^{*}}=\frac{(\varphi a-A)^{2}}{9 \varphi}, \quad k=i, j .
\end{aligned}
$$

Situation
strategy.

In this situation, the Cournot game between two imitation-innovation firms is utilized to construct the model. Without R\&D investment, there is no benefit of sharing technology spillover between each other, and it is not possible to reduce their own unit production cost. Since both firms choose an imitation strategy at this time, the price of imitation products is $p_{i, M}$. Therefore, the firms' profit maximization is transformed into

$$
\left\{\begin{array}{l}
\max _{q_{i}} \pi_{i, M}^{C}=\left[\varphi\left(a-q_{i}-q_{j}\right)-A\right] q_{i}, \\
\max _{q_{j}} \pi_{j, M}^{C}=\left[\varphi\left(a-q_{i}-q_{j}\right)-A\right] q_{j} .
\end{array}\right.
$$

By the backward induction method, the optimal production $q_{k}^{*}$ is solved. The optimal payoff of firm $i$ and firm $j$ can be obtained by substituting the profit function as follows:
In general, a new technology to reduce marginal costs is always subject to risks $[14,60]$. This suggests that the innovation-leading firm will encounter all sorts of uncertainty risks that may result in a decrease in profit, such as the difficulty of technology research and development, the alternative technology risk, policy risk, and the risk of changes in market demand. Therefore, an innovation risk factor $\delta$ is introduced. The greater the innovation risk is, the lower the innovation payoff will be. Innovation payoffs can be expressed as

$$
\begin{aligned}
\pi_{i, C}^{C} & =(1-\delta) \pi_{i, C}^{C^{*}}, \\
\pi_{j, C}^{C} & =(1-\delta) \pi_{j, C}^{C^{*}}, \\
\pi_{i, C}^{S} & =(1-\delta) \pi_{i, C}^{S^{*}}, \\
\pi_{j, C}^{S} & =(1-\delta) \pi_{j, C}^{S^{*}} .
\end{aligned}
$$


According to the evolutionary game theory, the replicator dynamic equation can be constructed to analyze the evolutionary stability of the strategies. The evolutionary game framework of a single group is applied for analysis. We assume that there are many firms paired to compete for production in the market, and the actual proportion of firms in the group choosing innovation strategy and imitation strategy is $x$ and $1-x$, respectively. Therefore, the expected payoff of innovation strategy and imitation strategy adopted by any firm $k$ in the group is as follows:

$$
\begin{aligned}
U_{k, C} & =x \pi_{k, C}^{C}+(1-x) \pi_{k, C}^{S}, \\
U_{k, M} & =x \pi_{k, M}^{S}+(1-x) \pi_{k, M}^{C}, \\
\bar{U}_{k} & =x U_{k, C}+(1-x) U_{k, M} .
\end{aligned}
$$

According to the above analysis, the replicator dynamic equation can be obtained:

$$
F(x)=\frac{\mathrm{d} x}{\mathrm{~d} t}=x\left(U_{k, C}-\bar{U}_{i}\right)=x(1-x)\left(U_{k, C}-U_{k, M}\right) .
$$

The evolutionary stability of innovation and imitation strategy can be obtained by solving the replicator dynamic equation.

\subsection{The Improved Game Model Based on Prospect Theory.} According to prospect theory, the decision-making behavior of the firm highly depends on the perception of returns [69]. That is, the firm often tends to maintain the previous decision when perceiving gain but changes the decision when perceiving loss. This can be represented by the gain-loss utility, and the shape of the function is S-shaped, as suggested by Tversky and Kahneman [43], as shown in Figure 1.

According to Figure 1, the gain-loss utility $f(\Delta \pi)$ has the following characteristics. $\Delta \pi$ can be seen as the difference between the final payoff $\pi$ and the reference point $r$. When $\Delta \pi>0$, which means that the perception of choosing this strategy is gains, the firms will show satisfaction and continue to tend to adopt this strategy. When $\Delta \pi<0$, which indicates that the perception is losses, the firms will show loss aversion and will not be inclined to adopt this strategy in the future.

$$
f(\Delta \pi)= \begin{cases}(\pi-r)^{\alpha}, & \pi>r, \\ -\lambda(r-\pi)^{\beta}, & \pi<r .\end{cases}
$$

In addition, $f(\Delta \pi)<0 \prime \prime(\Delta \pi>0)$ and $f(\Delta \pi)>0 \prime \prime$ $(\Delta \pi<0)$ mean that firms show risk aversion in the face of gains and risk-seeking in the face of losses, respectively. $\alpha$ and $\beta(0<\alpha, \beta<1)$ represent the marginal diminishing degree of gains and losses. $\lambda(\lambda \geq 1)$ refers to the coefficient of loss aversion, meaning that the decision-making firm is more sensitive to losses for the same degree of gains.

However, in reality, this type of decision-making behavior that mainly focuses on the gain-loss utility cannot reflect the real decision-making process of the firm [70]. For example, when a firm makes a strategic investment decision, it will affect both the payoff gap with other firms and its

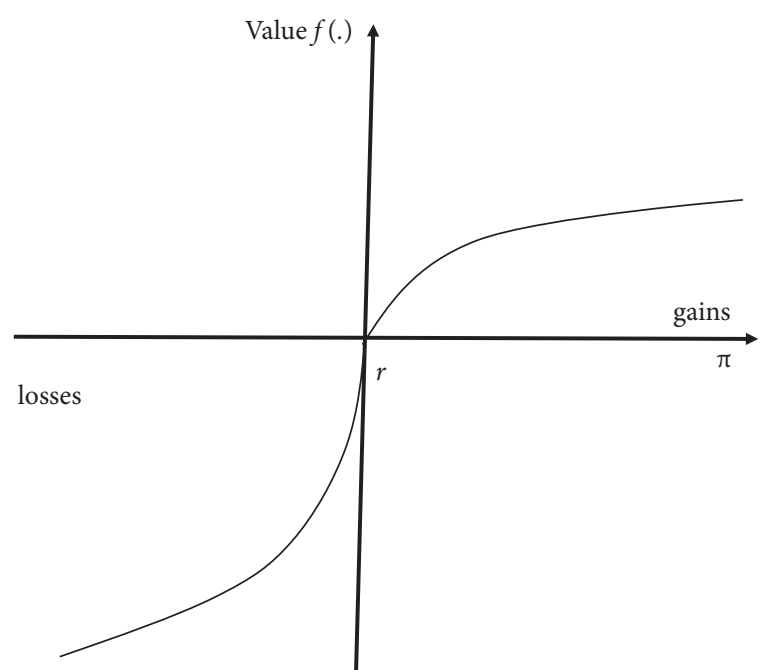

Figure 1: The curve of an S-shaped value function. Note: $f(\Delta \pi)$ is the gain-loss utility, $r$ is the reference point, and $\pi$ is the final payoff.

aspiration level. It is worth noting that because the strategy selection of the rival firm is based on incomplete information, there will be a variety of different strategy combinations. That is, the aspiration level (i.e., reference point) of the firm is not unique and will be adjusted according to the competition model formed by the combination of strategies of both firms. We assume that there are $M$ different situations in which the reference point in the $j$-th situation is represented by $r_{j}$, and the probability of each situation is represented by $p_{j}$. Therefore, to analyze the decision-making behavior of firms more reasonably, this paper introduces an improved utility function, which considers both rational expected and gain-loss utility. The utility function specifically is expressed as

$$
V=\sum_{i=1}^{N} \chi_{i} \pi_{i}+\sum_{i=1}^{N} \chi_{i}\left[\sum_{j=1}^{M} p_{j} f\left(\pi_{i}-r_{j}\right)\right] .
$$

The first term in the equation is rational expected utility, and the second term is gain-loss utility.

In addition, it is worth noting that the probability weighting function of the utility function proposed by Köszegi and Rabin [21] is still linear, and a large number of studies have confirmed the universality of the nonlinear probability weighting function [71]. One commonly used function form for a probability weighting function $w(\cdot)$ is given by

$$
w(\chi)=\frac{\chi^{\phi}}{\left[\chi^{\phi}+(1-\chi)^{\phi}\right]^{(1 / \phi)}} .
$$

The probability weighting function has the same inverted $S$ shape, as shown in Figure 2, which maps the true probabilities $\chi$ on to the unit interval. Generally, $w(\chi)$ satisfies $w(0)=0, w(1)=1$, with $w(\chi)>\chi$ for all $\chi<\bar{\chi}$ and $w(\chi)<\chi$ for all $\chi>\bar{\chi}$. This indicates that there is a general tendency to overestimate the low probability events and underestimate 


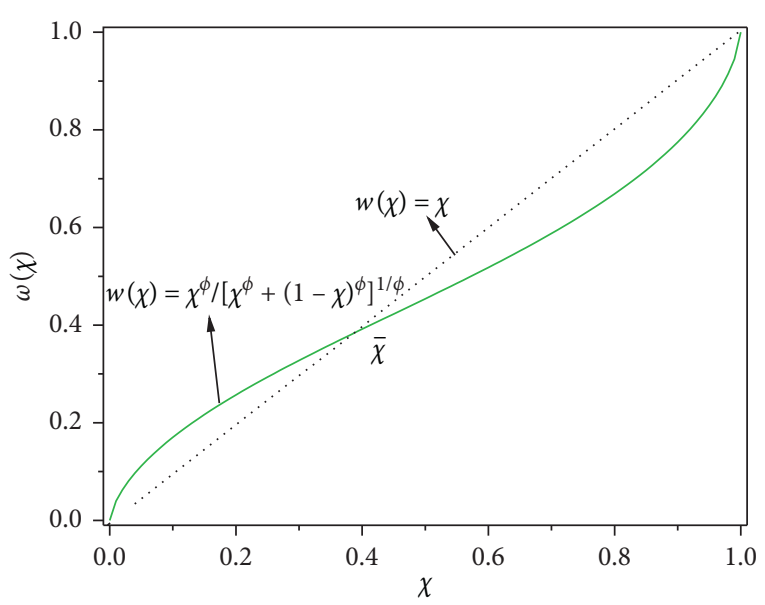

FIGURE 2: The curve of the probability weighting function.

the high probability events. $\phi$ is an adjustable parameter that controls the curvature of the probability weighting function.

Therefore, this paper replaces the linear probability weighting function in the gain-loss utility with the nonlinear probability weighting function:

$$
V=\sum_{i=1}^{N} \chi_{i} \pi_{i}+\sum_{i=1}^{N} w\left(\chi_{i}\right)\left[\sum_{j=1}^{M} p_{i} f\left(\pi_{i}-r_{j}\right)\right] .
$$

3.4. The Payoff Matrix Based on Prospect Theory. According to prospect theory, perception payoff is described as the change in relative payoff compared with their current reference point rather than upon final payoff. By comparing the actual payoff with the reference points, the difference reflects the gains or losses. For example, when firm $i$ adopts the innovation strategy since it is unknown which strategy the firm $j$ will adopt, there may be two possible payoff results, as shown in Table $1, \pi_{i, C}^{C}$ and $\pi_{i, C}^{S}$. If the firm $i$ adopts $\pi_{i, C}^{C}$ as the reference point, the perception payoffs are 0 and $\pi_{i, C}^{S}-\pi_{i, C}^{S}$, while if the firm $i$ adopts $\pi_{i, C}^{S}$ as the reference point, the perception payoffs are $\pi_{i, C}^{C}-\pi_{i, C}^{S}$ and 0 , respectively. Similarly, when the firm $i$ adopts the imitation strategy, there may be two possible payoff results, $\pi_{i, M}^{S}$ and $\pi_{i, M}^{C}$, then the perception payoffs are 0 and $\pi_{i, M}^{C}-\pi_{i, M}^{S}$ under the reference point $\pi_{i, M}^{S}$, and the perception payoffs are $\pi_{i, M}^{S}-\pi_{i, M}^{C}$ and 0 under the reference point $\pi_{i, M}^{C}$. Furthermore, we assume that the probabilities of two possible reference points in the case of innovation strategy or imitation strategy are $p$ and $1-p$. The selection of the preference point under uncertain conditions can be regarded as the decision-making attitude [61], that is, $p$ and $1-p$ represent the degree of pessimism and optimism of the decision maker, respectively. When the value of $p$ is large, it means that the firm believes that its rival will adopt the same strategy and pessimistically considers that it will compete fiercely with its rival in the market. In contrast, when $p$ is smaller, it means that the firm believes that its rival will adopt a different strategy and expects optimistically to obtain a greater payoff. Therefore, by comparing the payoffs of firm $i$ and firm $j$ with their corresponding possible reference points, respectively, a new perception payoff matrix can be obtained, as shown in Table 2.

According to the prospect theory that considers rational expectation and gain-loss utility, the prospect value of the innovation strategy or imitation strategy can be obtained. Assume that the actual proportions of firms in the group choosing an innovation strategy and imitation strategy are $x$ and $1-x$, respectively. Owing to the information and subjective judgment bias, the firms in the group will subjectively think that the proportions of choosing an innovation strategy and imitation strategy in the group are $w(x)$ and $w(1-x)$. Therefore, the prospect values of the innovation strategy and the imitation strategy adopted by any firm $i$ in the group are as follows:

$$
\begin{aligned}
V_{k, C} & =x \pi_{k, C}^{C}+(1-x) \pi_{k, C}^{S}-w(x)\left[(1-p) \lambda\left(-\left(\pi_{k, C}^{C}-\pi_{k, C}^{S}\right)\right)^{\beta}\right]+w(1-x)\left[p\left(\pi_{k, C}^{S}-\pi_{k, C}^{C}\right)^{\alpha}\right] \\
V_{k, M} & =x \pi_{k, M}^{C}+(1-x) \pi_{k, M}^{C}-w(x)\left[(1-p) \lambda\left(-\left(\pi_{k, M}^{S}-\pi_{k, M}^{C}\right)\right)^{\alpha}\right]+w(1-x)\left[p \lambda\left(-\left(\pi_{k, M}^{S}-\pi_{k, M}^{S}\right)\right)^{\beta}\right] \\
\bar{V}_{k} & =x V_{k, C}+(1-x) V_{k, M} .
\end{aligned}
$$

According to the above analysis, the duplicator dynamic equation can be obtained:

$$
F(x)=x\left(V_{k, C}-\bar{V}_{k}\right)=x(1-x)\left(V_{k, C}-V_{k, M}\right) .
$$

The evolutionary stability of firm innovation and imitation strategy can be obtained by solving the replicator dynamic equations.

\section{The Simulation Results}

Simulation analysis is used to analyze the evolution stability results by setting different parameter scenarios. Based on the research of Tversky and Kahneman [43] and Dhami [70], the loss aversion coefficient $\lambda$ is set as 2.25 , the risk preference coefficients $\alpha$ and $\beta$ are set to 0.89 and 0.92 , the curvature of the probability weighting function $\phi$ is set to 0.69 , the $R \& D$ 
TABLE 2: The payoff matrix based on the prospect theory.

\begin{tabular}{cccc}
\hline & & Firm $j$ \\
Firm $i$ & Innovation strategy $(C)$ & $\prod_{i, C}^{C}=\left\{0, \pi_{i, C}^{C}-\pi_{i, C}^{S}\right\}, \prod_{j, C}^{C}=\left\{0, \pi_{j, C}^{C}-\pi_{j, C}^{S}\right\}$ & $\prod_{i, C}^{S}=\left\{\pi_{i, C}^{S}-\pi_{i, C}^{C}, 0\right\}, \prod_{j, M}^{S}=\left\{0, \pi_{j, M}^{S}-\pi_{j, M}^{C}\right\}$ \\
& Imitation strategy $(M)$ & $\prod_{i, M}^{S}=\left\{0, \pi_{i, M}^{S}-\pi_{i, M}^{C}\right\}, \prod_{j, C}^{S}=\left\{\pi_{j, C}^{S}-\pi_{j, C}^{C}, 0\right\}$ & $\prod_{i, M}^{C}=\left\{\pi_{i, M}^{C}-\pi_{i, M}^{S}, 0\right\}, \prod_{j, M}^{C}=\left\{\pi_{j, M}^{C}-\pi_{j, M}^{S}, 0\right\}$ \\
\hline
\end{tabular}

cost coefficient $\gamma$ is set to 2 , the market potential capacity $a$ is set to 10 , and the marginal cost $A$ of production is set to 8 . In addition, the initial actual proportion of firms in the group choosing the innovation strategy is $x=0.5$. This article further reveals the mechanisms of the behavioral biases on firms' technological strategic choices through simulation analysis of important factors such as intellectual property protection, patent fees, and decision-making attitudes. To compare and analyze the influence of the behavioral biases such as reference point dependence, loss aversion, and probability weighting on firms' technological strategic choices, the corresponding results of the basic game model are also presented.

\subsection{The Effect of Intellectual Property Protection Intensity.} The mechanism of intellectual property protection on firm decision-making behavior is analyzed first. The intensity of intellectual property protection describes the efforts of firms to implement patent protection and modularization to protect their interests from infringement. The stronger the intensity of intellectual property protection, the less knowledge the other firms will acquire through technology spillover. This paper divides the strength of intellectual property protection into five levels: $\theta=0 \theta=0.3, \theta=0.5$, $\theta=0.8$, and $\theta=1$; the innovation risk is divided into three levels: $\delta=0.3, \delta=0.5$, and $\delta=0.8$. The patent fees are fixed as $\rho=50 \%$, the consumers' price preference is set as $\varphi=1$, and the decision-making attitude of the firm is set as neutral, $p=0.5$. The simulation results are shown in Figures 3 and 4 .

As can be seen from Figure 3, with the increase in intellectual property protection $\theta$, the proportion of firms that choose the innovation strategy will also increase, and the lower the innovation risk ( $\delta=0.3$ and $\delta=0.5$ ), the greater the proportion of firms that choose the innovation strategy. This shows that intellectual property protection can effectively improve firms' innovation initiative.

Compared with the results in Figure 3, as can be seen from Figure 4, with the increase in the intellectual property protection, there is a general trend that the strategy selection of firms will change from an imitation strategy to an innovation strategy even with the high innovation risks $(\delta=0.8)$. This phenomenon can be further inferred; in addition to improving intellectual property protection, the new mechanism to promote the innovation lies in the behavioral biases such as reference point dependence and loss aversion. By analyzing the perception payoff caused by different strategy selections, it can be found that firms are more sensitive to the loss caused by imitation strategy, as shown in Figure 5.
As can be seen from Figure 5, taking firm $i$ as an example, there are two possible results $\left(\pi_{i, C}^{C}, \pi_{i, C}^{S}\right)$ or $\left(\pi_{i, M}^{C}, \pi_{i, M}^{S}\right)$ under the conditions that firm $i$ adopts the innovation strategy or adopts the imitation strategy, respectively. The differences $\left(\Delta V^{C}=\pi_{i, C}^{S}-\pi_{i, C}^{C}, \Delta V^{M}=\pi_{i, M}^{S}-\pi_{i, M}^{C}\right)$ between the two results are the perception payoff. A positive value $\left(+\Delta V^{C},+\Delta V^{M}\right)$ represents the perception of gain, and a negative value $\left(-\Delta V^{C},-\Delta V^{M}\right)$ represents the perception of loss. It can be seen that if the firm adopts the imitation strategy since it does not need to pay the R\&D cost, it can gain technology spillover by paying a certain patent fees to reduce its own production cost. Thus, it can be reasonably inferred that $\left|\pi_{i, M}^{S}-\pi_{i, M}^{C}\right|>\mid \pi_{i, C}^{S}-\pi_{i, C}^{C}$. Furthermore, when both $\left|\pi_{i, C}^{S}-\pi_{i, C}^{C}\right|$ and $\left|\pi_{i, M}^{S}-\pi_{i, M}^{C}\right|$ are in the gain domain, the gap of the difference $+\Delta V^{C}$ and $+\Delta V^{C}$ is small, but when both $\left|\pi_{i, C}^{S}-\pi_{i, C}^{C}\right|$ and $\left|\pi_{i, M}^{S}-\pi_{i, M}^{C}\right|$ are in the loss domain, the gap of difference $-\Delta V^{C}$ and $-\Delta V^{M}$ is relatively obvious. Therefore, the losses caused by the imitation strategy are relatively larger than the gains brought by the innovation strategy, so under the influence of loss aversion, firms will eventually tend to adopt the innovation strategy.

4.2. The Effect of Patent Fees. Next, the effect of patent fees on firm decision-making behavior will be analyzed. The value of patent fees $\rho$ can be set as three levels: $\rho=30 \%, \rho=50 \%$, and $\rho=80 \%$. The innovation risk can be set as three levels: $\delta=0.3, \delta=0.5$, and $\delta=0.8$, the intellectual property protection intensity is set as $\theta=0.5$, the consumers' price preference is set as $\varphi=1$, and the decision-making attitude of the firm is set as neutral, $p=0.5$. The simulation results are shown in Figures 6 and 7.

As can be seen from Figure 6, under the lower level of innovation risks ( $\delta=0.3, \delta=0.5$ ), increasing patent fees can significantly increase the proportion of firms that choose innovation strategies. Even in a high innovation risk environment $(\delta=0.8)$, increasing patent fees can delay the time to finally adopt an imitation strategy to a certain extent. The results show that under the combined effect of high patent fees and lower innovation risk, firms are more inclined to adopt an innovation strategy instead of an imitation strategy.

Compared with the results in Figure 6, it can be seen from Figure 7 that when firms consider the behavioral biases in the process of strategy selection, increasing patent fees can significantly promote the proportion of innovative firms even under higher innovation risk conditions $(\delta=0.8)$. There are two main reasons for this: (1) a higher patent fee can stimulate the enthusiasm of firms to adopt an innovation strategy and protect the innovation interests of firms; and (2) relying on behavioral biases, such as reference points dependence and loss aversion, a higher patent fees will make 


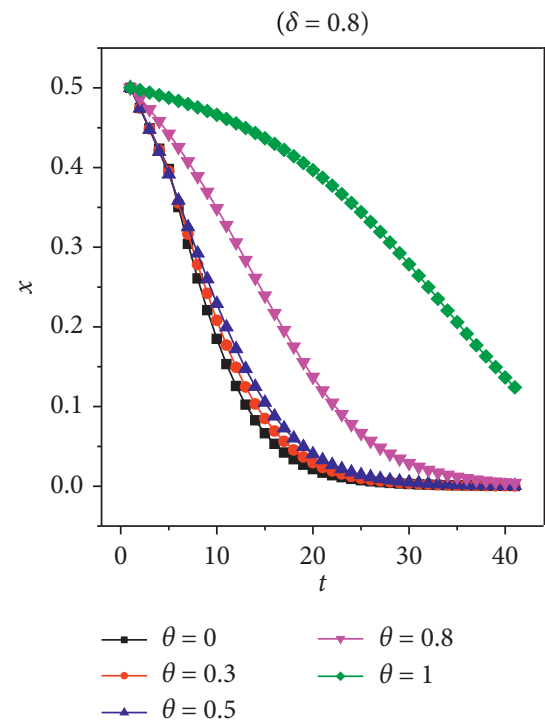

(a)

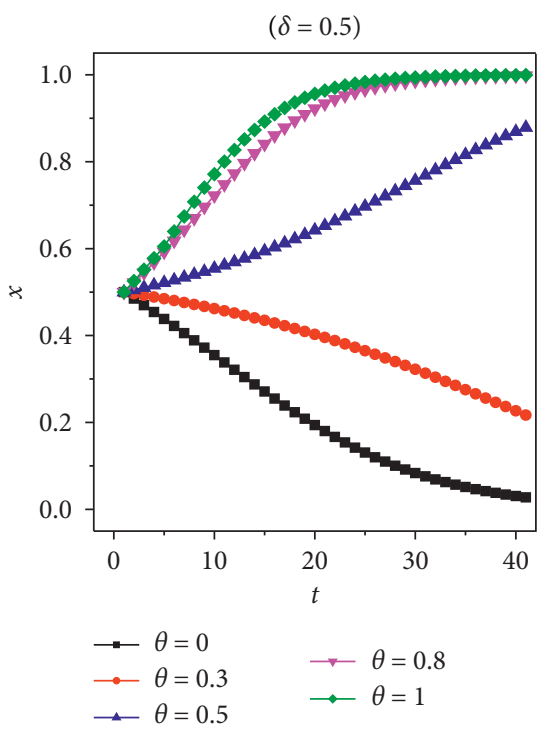

(b)

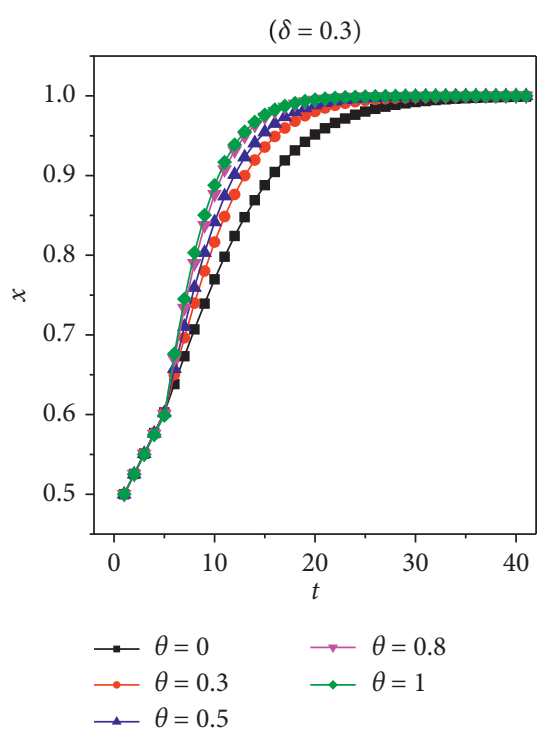

(c)

FIGURE 3: The proportion of innovation-leading firms in the group for different intellectual property protection intensity $\theta$ on three levels of the innovation risk $\delta$ based on the basic game model.

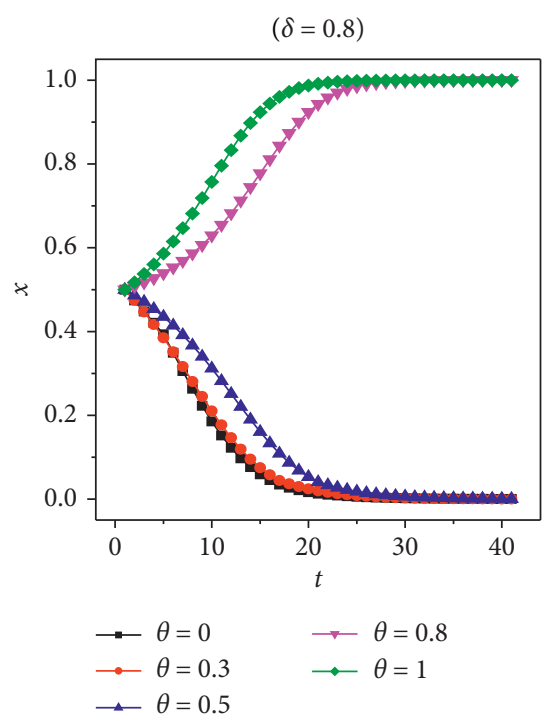

(a)

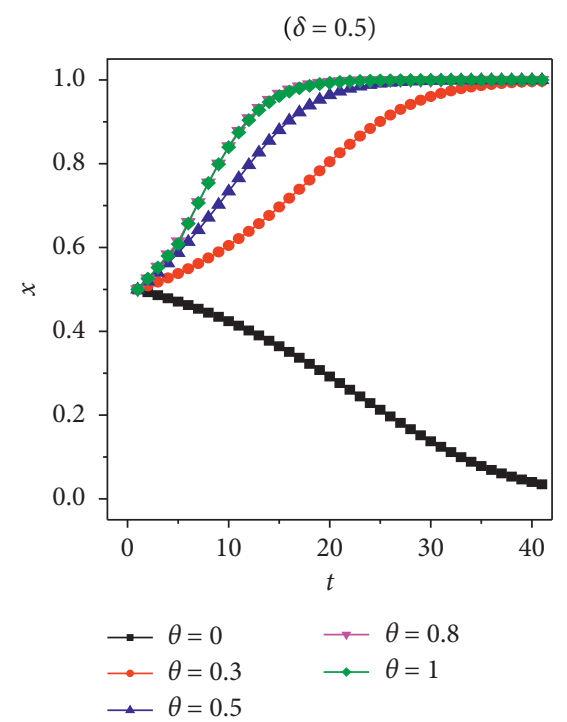

(b)

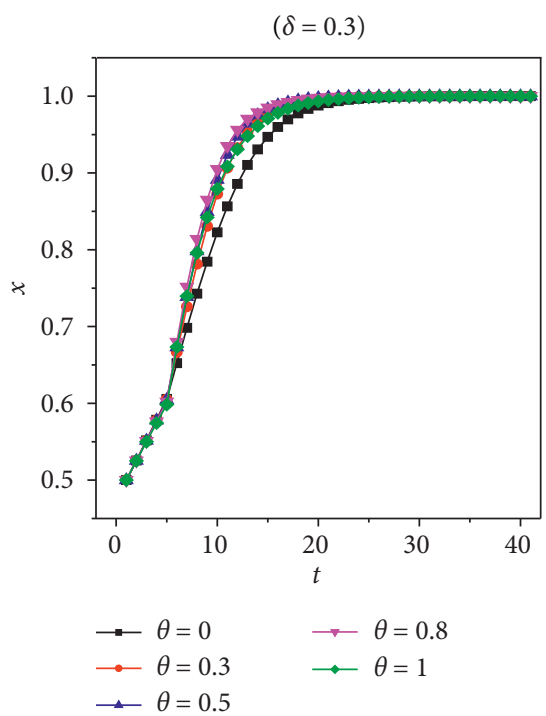

(c)

FIGURE 4: The proportion of innovation-leading firms in the group for different intellectual property protection intensity $\theta$ on three levels of the innovation risk $\delta$ based on the improved game model.

firms perceive that the loss of the imitation strategy will exceed the gain of the innovation strategy to a great extent, as shown in Figure 6. Therefore, the effect of loss aversion will eventually force the firm to adopt the innovation strategy.

4.3. The Effect of Decision-Making Attitudes. The mechanism of the firm's decision-making attitude on strategic choices is analyzed further. The decision-making attitude of firms is divided into five levels: complete pessimistic $(p=1)$, partial pessimistic $(p=0.3)$, neutral $(p=0.5)$, partially optimistic $(p=0.8)$, and completely optimistic $(p=0)$. The innovation risk is divided into three levels: $\delta=0.3, \delta=0.5$, and $\delta=0.8$. The intellectual property protection intensity is fixed as $\theta=0.5$, the consumers' price preference is set as $\varphi=1$, and the patent fees are fixed as $\rho=50 \%$. The simulation results are shown in Figure 8.

As can be seen from Figure 8, under different conditions of innovation risk with the firm's decision-making attitude changing from complete pessimism $(p=1)$ to complete optimism $(p=0)$, the firm's enthusiasm for choosing the innovation strategy will increase. Especially under high risk 


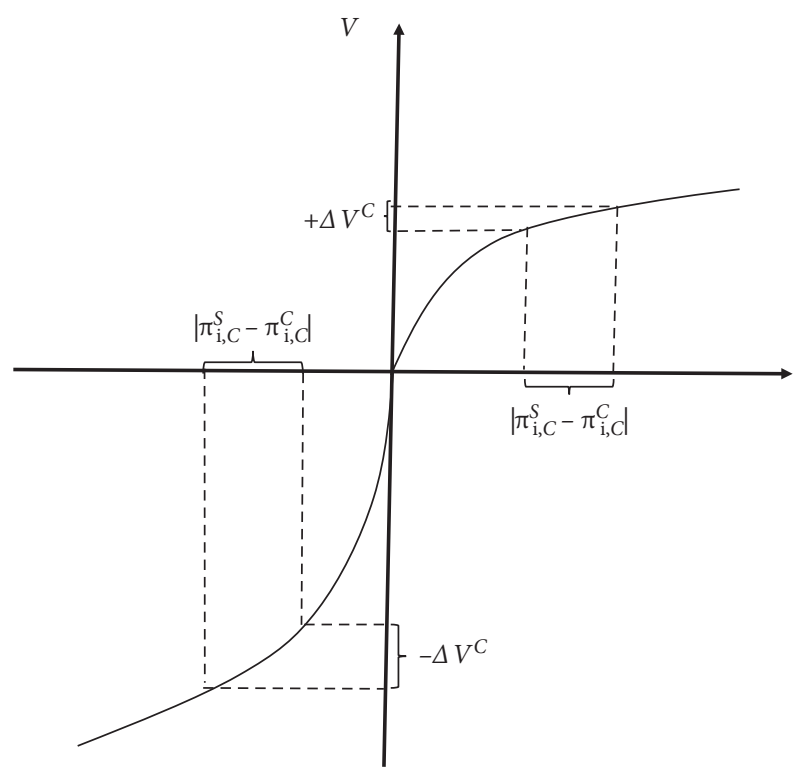

(a)



(b)

FIGURE 5: The difference of perception payoff between innovation (a) and imitation (b).

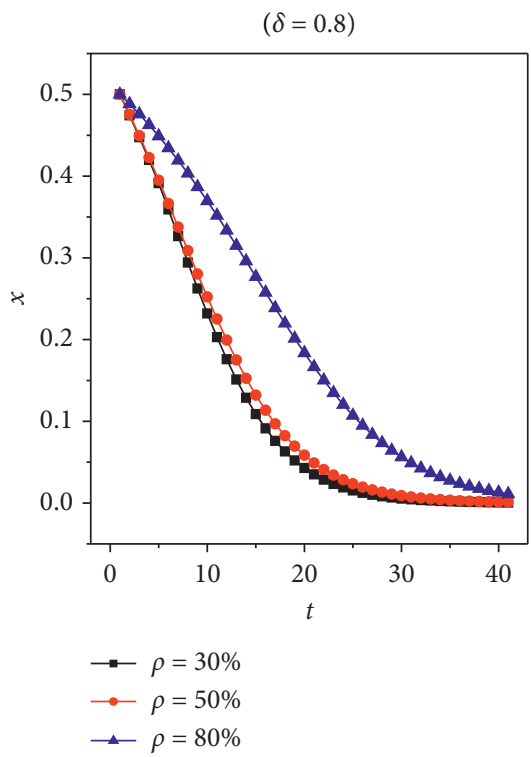

(a)

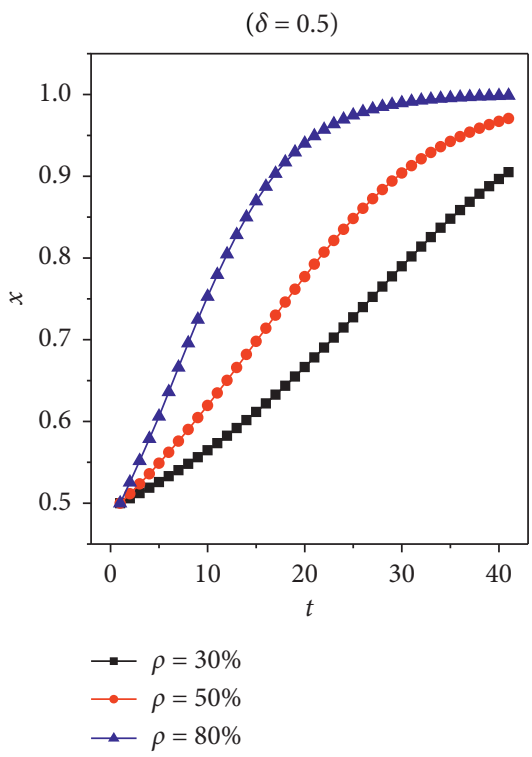

(b)

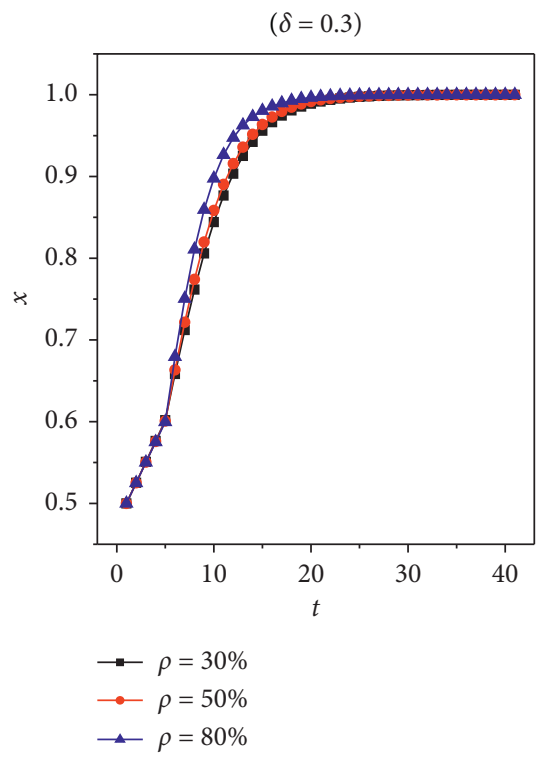

(c)

FIGURE 6: The proportion of innovation-leading firms in the group for different patent fee intensity $\rho$ on three levels of the innovation risk $\delta$ based on the basic game model.

conditions, the more optimistic the firm's decision-making attitude is, the higher the proportion of firms that choose the innovation strategy is. The principal reason for this is that in the process of strategic choices, if the firm optimistically believes that the other firm will adopt a different strategy from its own, it will to some extent adopt an innovation strategy with a first-mover advantage to obtain more market opportunities. Additionally, the firm perceives that the loss of imitation strategy will far exceed the gain of the innovation strategy. Therefore, under the effect of loss aversion, the firm will eventually tend to adopt the innovation strategy.

4.4. The Effect of the Consumers' Price Preference. Finally, this study analyzes the mechanism of the consumers' price preference on strategic choices. Consumers' price preferences are divided into five levels: $\varphi=0.1, \varphi=0.3, \varphi=0.5$, $\varphi=0.7$, and $\varphi=0.9$. The innovation risk is divided into three levels: $\delta=0.3, \delta=0.5$, and $\delta=0.8$, the intellectual property 


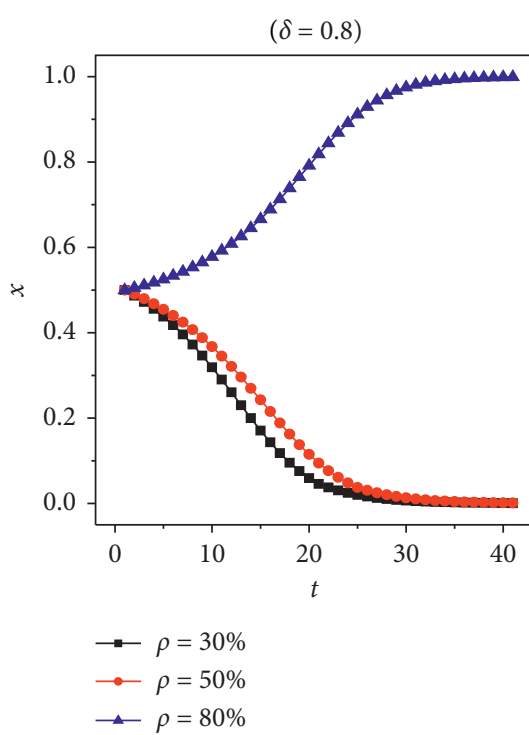

(a)

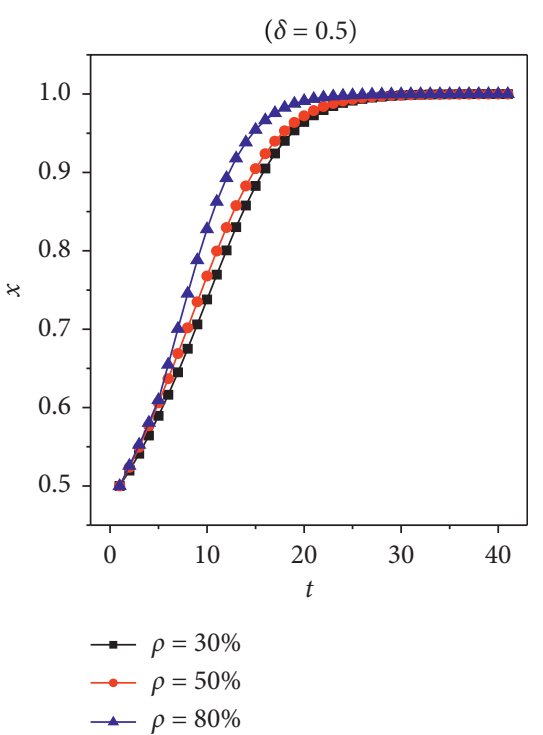

(b)

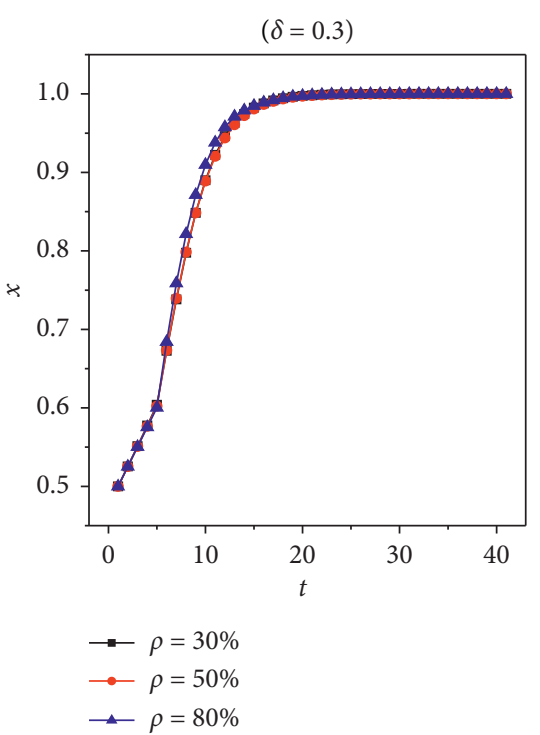

(c)

FiguRE 7: The proportion of innovation-leading firms in the group for different patent fee intensity $\rho$ on three levels of the innovation risk $\delta$ based on the improved game model.

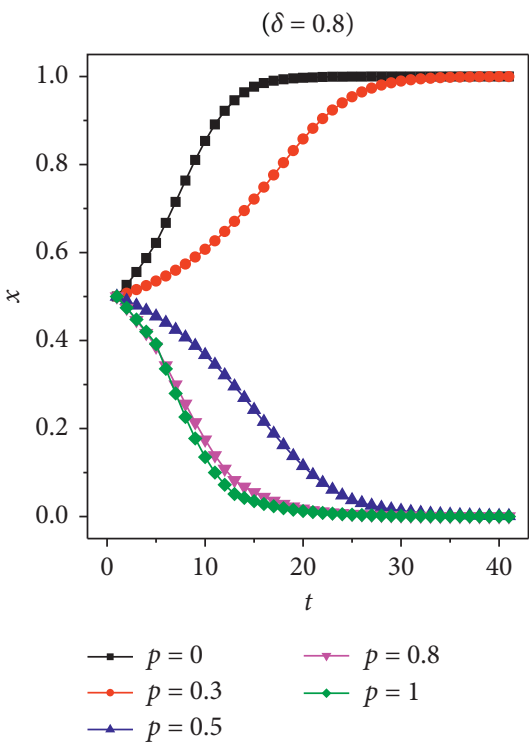

(a)

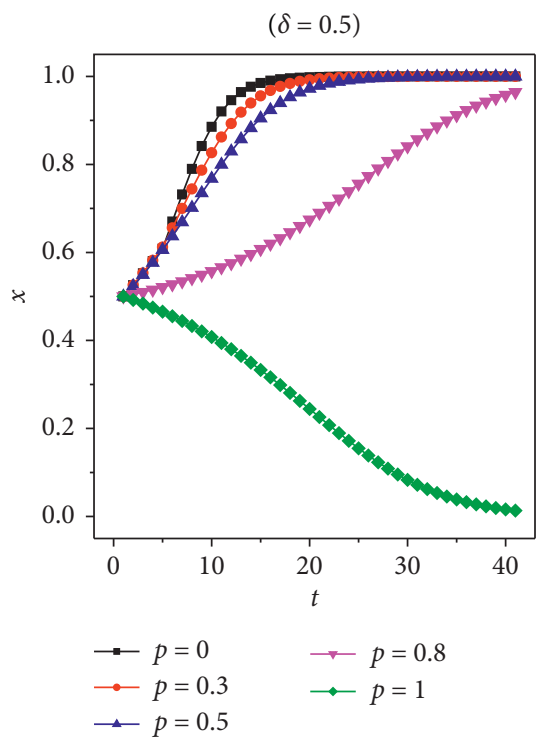

(b)

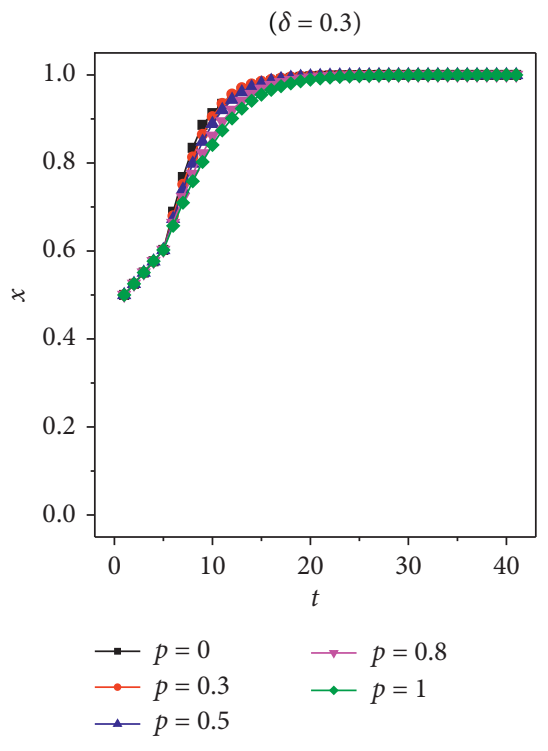

(c)

FIGURE 8: The proportion of innovation-leading firms in the group for different decision-making attitude $p$ on three levels of the innovation risk $\delta$ based on the improved game model.

protection intensity is fixed as $\theta=0.5$, the patent fees are fixed as $\rho=50 \%$, and the decision-making attitude of the firm is set as neutral, $p=0.5$. The simulation results are shown in Figure 9.

It can be seen from Figure 9 that when consumers' price preference for choosing innovative products and imitating products decreases (that is, as $\varphi$ increases), the number of firms that choose innovation strategy increases. The reason for this situation can be obtained by further observing the prices of products between innovation-leading firms and imitation-following firms. From Figure 10(a), it can be seen that as $\varphi$ continues to increase, there will be no difference in consumers' price preference for these two products, but because firms that choose the innovation strategy can obtain new profit growth by charging patent fees, more firms will choose the innovation strategy. However, this does not mean that consumers' price preference has no effect on innovation. To further understand the reason for this outcome, we observe the relationship between the smaller $\varphi$ and $x$ in the steady state, as shown in Figure 10(b).

Through Figure 10(b), it can be identified that there is a partial U-shaped relationship between the smaller $\varphi$ and $x$ in 




(a)

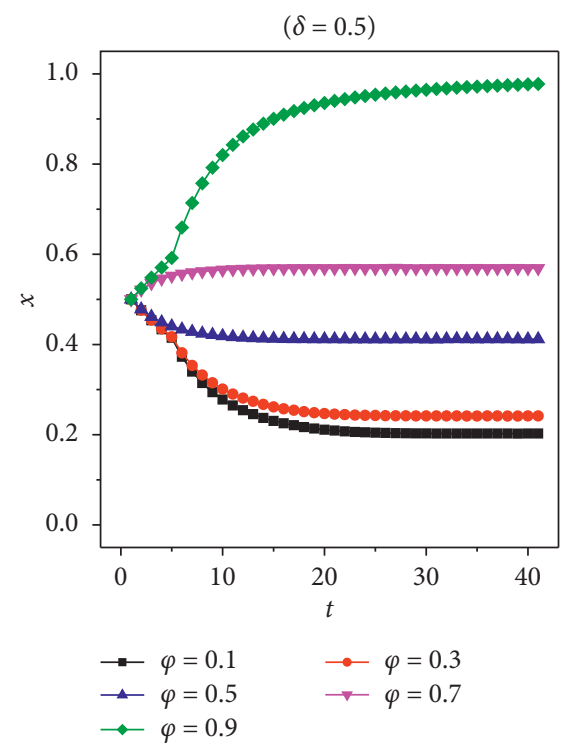

(b)

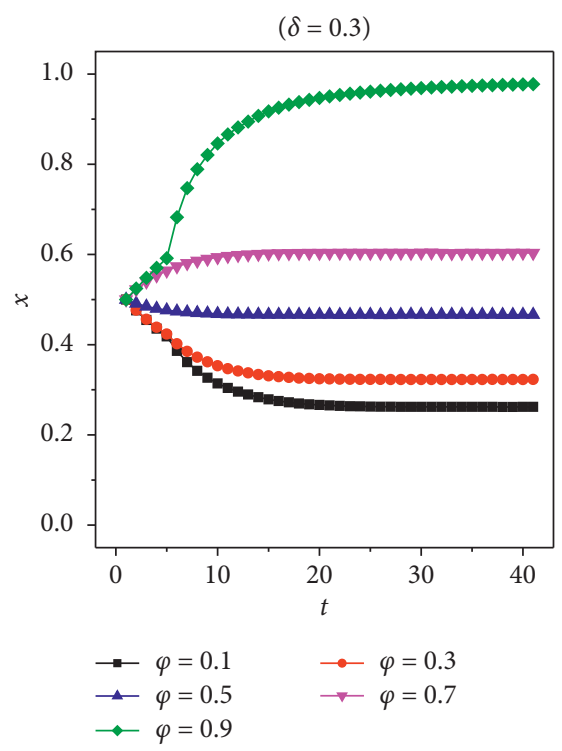

(c)

FIgURE 9: The proportion of innovation-leading firms in the group for different consumers' price preference $\varphi$ on three levels of the innovation risk $\delta$ based on the improved game model.

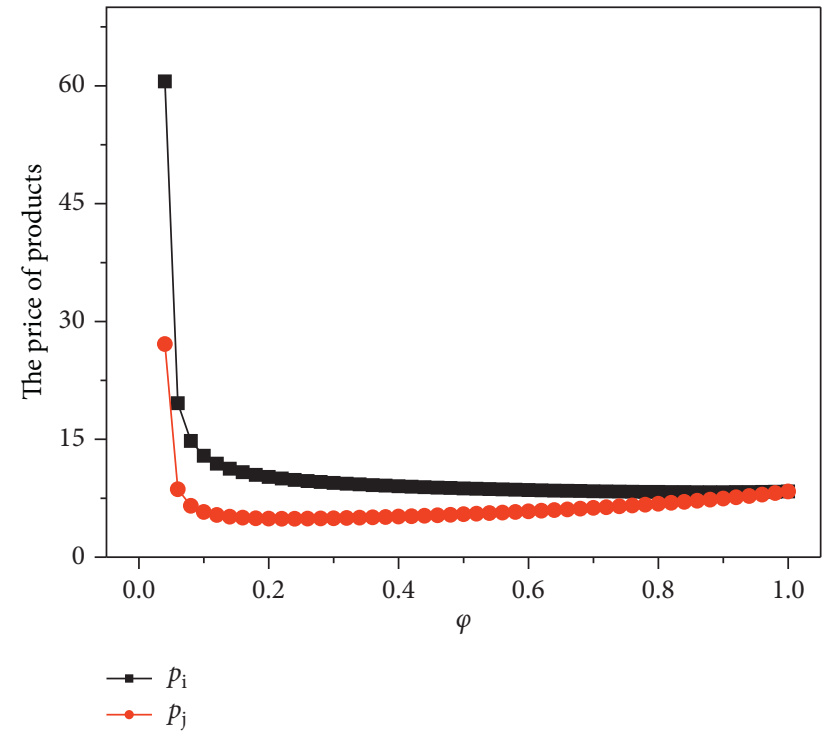

(a)

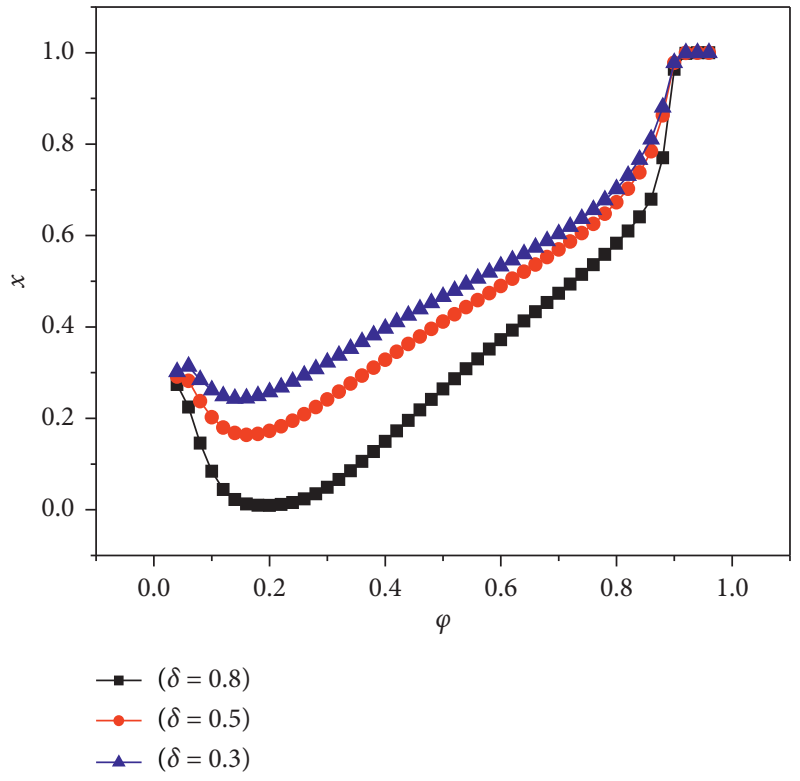

(b)

FIGURE 10: (a) The prices of products between innovation-leading firms and imitation-following firms for different consumers' price preference $\varphi$ with the innovation risk $\delta=0.5$ and (b) the relationship between the proportion of innovation-leading firms in the group and different consumers' price preference $\varphi$ on three levels of the innovation risk $\delta$ based on the improved game model.

the steady state under different innovation risks, indicating that a very small $\varphi$ is beneficial to choosing the innovation strategy to some extent. The reason for this phenomenon is also evident. When $\varphi$ is very small, consumers have a very large price preference for innovation products, and consumers are more willing to pay high prices for innovation products, as shown in Figure 10(a). Therefore, firms that choose an innovation strategy can obtain greater profit returns, which will increase the probability of firms choosing an innovation strategy. With the gradual increase in $\varphi$, a certain degree of substitution appears between innovation products and imitation products. At this time, consumers' price preference for innovation products may begin to decrease, and the price difference between innovation products and imitation products will gradually shrink. Although firms that choose an innovation strategy can obtain 
certain profit growth by charging patent fees, this part of the profit growth cannot offset the loss of profit caused by innovation costs and innovation risks. Therefore, firms that choose an imitation strategy at this time may obtain more profit margins. Therefore, the number of firms choosing an innovation strategy will decrease. As $\varphi$ further increases, the substitution of innovation products and imitation products further improves. As a result, the price difference between innovation products and imitation products decreases, but because firms that choose an innovation strategy can obtain more profit growth by charging patent fees, the extra profit is enough to offset the loss caused by innovation costs and innovation risks. Therefore, firms that choose innovation strategies will continue to increase.

\section{Conclusions and Discussion}

This paper analyzes how the firms' technological strategic choices between innovation and imitation are affected by behavioral biases. First, behavioral biases such as reference point dependence, loss aversion, and probability weighting can be modeled based on the prospect theory. Second, the interactive process among firms is described by a Cournot or Stackelberg game model with a technology spillover effect and intellectual property protection. By setting different parameters and performing simulation analysis, the following important conclusions are obtained:

(1) Innovation risk, as a concentrated reflection of the technology, market, and policy environment, is an important factor affecting a firm's decision-making behavior. The higher the innovation risk, the greater its impact on the firm's innovation payoff. Once the innovation risk exceeds the range that the firm can tolerate, even under high intellectual property protection, high patent fees, and optimistic innovation decision-making attitudes, it will not arouse the firm enthusiasm for innovation.

(2) Increasing intellectual property protections and the patent fees for technology transfer can effectively control the technology spillover. By increasing the difficulty and cost of the imitation-following firms, we can maintain the enthusiasm for innovation and safeguard the benefits of innovation. Therefore, increasing the awareness of intellectual property protection and strengthening the role of intellectual property protection will be more conducive to the cultivation of firm innovation capabilities.

(3) A partial U-shaped relationship between the consumers' price preference and innovation is presented, namely, consumers' price preference for innovation products and imitation products is extremely large or smaller, which can effectively improve the innovation. This conclusion suggests that increasing the enthusiasm of firms for innovation, on the one hand, can greatly increase the difference between innovation products and imitation products such that consumers are willing to pay the higher prices of innovation products and innovation- leading firms obtain high profits. On the other hand, by increasing the substitutability of innovation products and imitation products, under the combined effect of consumers' price preference and technology transfer, firms may have a larger market share when choosing an innovation strategy. It is worth noting that through the second method, the profit growth of innovation products brought about by the combined effect of consumers' price preference and technology transfer must be enough to offset the loss caused by innovation costs and innovation risks.

(4) Compared with the results based on the basic model, the behavioral biases such as reference point dependence, loss aversion, and probability weighting will significantly affect a firm's decision-making behavior and increase the innovation enthusiasm. These behavioral biases will change the perception payoff and suggest that the losses caused by the imitation strategy will be higher than the gains brought about the innovation strategy. Therefore, under the influence of loss aversion, the firm will eventually prefer to adopt the innovation strategy. Once the innovation behavior is formed, it will be further strengthened through the positive feedback mechanism.

In summary, the driving force behind the innovation should focus not only on the role of external factors such as intellectual property protection and patent fees but also on the firm's behavioral biases.

From the above research, it can be seen that innovation risk runs through the analysis of the full text and is the key focus of this article. The conclusions have confirmed that innovation risk has become one of the decisive factors in the success or failure of innovation and interacts with factors such as property rights protection, patent fees, decisionmaking attitudes, consumer price preferences, and other factors to jointly determine the outcome of innovation. However, because the meaning of innovation risk in the article is relatively simple and the situation under incomplete information has not been considered, we can supplement our work from some existing research conclusions considering incomplete information. Harrison and Sunar considered a problem of investment timing with incomplete information and multiple learning modes based on a continuous-time Bayesian framework [72]. The results indicate that the optimal learning and investment policy lie on a small number of critical values in terms of the single-mode selection problem. When extended to multiple learning modes, the analysis of both investment timing and dynamic subset selection decisions is required. In addition, Sunar et al. pointed out that the customer network, business size, and investment timing will also affect the competitive investment $[5,6]$.

These studies show that investment decisions under incomplete information will be affected not only by the firm's learning modes but also by consumers' network, heterogeneous customer demand, business size, and 
investment timing. This is not only a further verification of our article but also guides us in the direction of future research. Therefore, our future research will further consider investment decision making under incomplete information, taking into account factors such as learning modes, investment timing, and consumers networks into the research model.

\section{Data Availability}

The data used to support the findings of this study are available from the corresponding author upon request.

\section{Conflicts of Interest}

The authors declare that there are no conflicts of interest regarding the publication of this paper.

\section{Acknowledgments}

The authors acknowledge the financial support of the National Natural Science Foundation of China (grant no. 72061003), Initial Scientific Research Project on Talent Introduction of Guizhou University of Finance and Economics in 2020 (grant no. 2020YJ007), Initial Scientific Research Project on Talent Introduction of Guizhou University of Finance and Economics (grant no. 2018YJ28), and Guangxi Science and Technology Base and Talent Special Project (grant no. 2019AC20335).

\section{References}

[1] J. Li, H. Ren, C. Zhang, Q. Li, and K. Duan, "Substantive innovation or strategic innovation? Research on multiplayer stochastic evolutionary game model and simulation," Complexity, vol. 2020, Article ID 9640412, 15 pages, 2020.

[2] S. Braguinsky, S. Gabdrakhmanov, and A. Ohyama, "A theory of competitive industry dynamics with innovation and imitation," Review of Economic Dynamics, vol. 10, no. 44, pp. 729-760, 2007.

[3] Y. Shi and M. Pan, "Dynamics of social tolerance on corruption: an economic interaction perspective," Romanian Journal of Economic Forecasting, vol. 21, no. 2, pp. 135-141, 2018.

[4] Y. Su and Y.-Q. Yu, "Spatial agglomeration of new energy industries on the performance of regional pollution control through spatial econometric analysis," Science of the Total Environment, vol. 704, no. 2, Article ID 135261, 2020.

[5] N. Sunar, J. R. Birge, and S. Vitavasiri, "Optimal dynamic product development and launch for a network of customers," Operations Research, vol. 67, no. 3, pp. 770-790, 2019.

[6] N. Sunar, S. Yu, and V. G. Kulkarni, "Competitive investment with bayesian learning: choice of business size and timing," SSRN Electronic Journal, vol. 9, no. 9, Article ID 3408260, 2020.

[7] M. Hu, "Literature review on imitation innovation strategy," American Journal of Industrial and Business Management, vol. 8, no. 8, pp. 1777-1788, 2018.

[8] H. Dawid, M. Kopel, and P. M. Kort, "Innovation threats and strategic responses in oligopoly markets," Journal of Economic Behavior \& Organization, vol. 75, no. 2, pp. 203-222, 2010.
[9] A. Nagurney and D. Li, “A dynamic network oligopoly model with transportation costs, product differentiation, and quality competition," Computational Economics, vol. 44, no. 2, pp. 201-229, 2014.

[10] W. Zhou and X.-X. Wang, "On the stability and multistability in a duopoly game with R\&D spillover and price competition," Discrete Dynamics in Nature and Society, vol. 2019, Article ID 2369898, 20 pages, 2019.

[11] N. Takashima and Y. Ouchida, "Quality-improving R\&D and merger policy in a differentiated duopoly: Cournot and Bertrand equilibria," Managerial and Decision Economics, vol. 41, no. 7, pp. 1338-1348, 2020.

[12] C.-H. Sun, "A duality between cost-reducing R\&D versus quality-improving R\&D and welfare analysis in a hotelling model," Atlantic Economic Journal, vol. 41, no. 2, pp. 133-148, 2013.

[13] N. H. Phuc, "Imitation \& innovation in emerging countries: a conceptual framework for analysis," Journal on Innovation and Sustainability, vol. 6, no. 1, pp. 37-47, 2015.

[14] P. N. Golder and G. J. Tellis, "Pioneer advantage: marketing logic or marketing legend?" Journal of Marketing Research, vol. 30, no. 2, pp. 158-170, 1993.

[15] M. Lude and R. Prügl, "Risky decisions and the family firm bias: an experimental study based on prospect theory," Entrepreneurship Theory and Practice, vol. 43, no. 2, pp. 386-408, 2019.

[16] L. Deng and T. A. Pirvu, "Multi-period investment strategies under cumulative prospect theory," Journal of Risk and Financial Management, vol. 12, no. 2, pp. 83-92, 2019.

[17] S. J. Peterson, F. O. Walumbwa, K. Byron, and J. Myrowitz, "CEO positive psychological traits, transformational leadership, and firm performance in high-technology start-up and established firms," Journal of Management, vol. 35, no. 2, pp. 348-368, 2009.

[18] W. Song, Z. Chen, X. Wang, Q. Wang, C. Shi, and W. Zhao, "Environmentally friendly supplier selection using prospect theory," Sustainability, vol. 9, no. 3, p. 377, 2017.

[19] K. Ruggeri, S. Alí, M. L. Berge et al., "Replicating patterns of prospect theory for decision under risk," Nature Human Behaviour, vol. 4, no. 5, pp. 622-633, 2020.

[20] N. C. Barberis, "Thirty years of prospect theory in economics: a review and assessment," Journal of Economic Perspectives, vol. 27, no. 1, pp. 173-196, 2013.

[21] B. Köszegi and M. Rabin, "A model of reference-dependent preferences," The Quarterly Journal of Economics, vol. 121, no. 4, pp. 1133-1165, 2006.

[22] L. Wang, T. Xu, and J. Chen, "Research on decision-making behavior of crowdsourcing task based on loss aversion and incentive level," Kybernetes, vol. 49, no. 5, pp. 1-18, 2019.

[23] H.-K. Chung, P. Glimcher, and A. Tymula, "An experimental comparison of risky and riskless choice-limitations of prospect theory and expected utility theory," American Economic Journal: Microeconomics, vol. 11, no. 3, pp. 34-67, 2019.

[24] J. Bessen and E. Maskin, "Sequential innovation, patents, and imitation," The RAND Journal of Economics, vol. 40, no. 4, pp. 611-635, 2009.

[25] J. E. L. Bercovitz and J. M. de Figueiredo, "Innovation biases," Economic Performance and the Theory of the Firm, vol. 1, pp. 76-96, 1998.

[26] T. H. Ho, N. Lim, and C. F. Camerer, "Modeling the psychology of consumer and firm behavior with behavioral economics," Journal of Marketing Research, vol. 43, no. 3, pp. 307-331, 2006. 
[27] L. Baizhou and Y. Shi, "Research on ecological partner selection of ICT enterprises under the background of digital transformation: based on prospect theory and field theory," Management Review, vol. 32, no. 5, p. 165, 2020.

[28] A. Fiegenbaum and H. Thomas, "Attitudes toward risk and the risk-return paradox: prospect theory explanations," Academy of Management Journal, vol. 31, no. 1, pp. 85-106, 1988.

[29] H. R. Greve, "A behavioral theory of R\&D expenditures and innovations: evidence from shipbuilding," Academy of Management Journal, vol. 46, no. 6, pp. 685-702, 2003.

[30] R. M. Wiseman and C. Catanach, "A longitudinal disaggregation of operational risk under changing regulations: evidence from the savings and loan industry," Academy of Management Journal, vol. 40, no. 4, pp. 799-830, 1997.

[31] J. C. Short and T. B. Palmer, "Organizational performance referents: an empirical examination of their content and influences," Organizational Behavior and Human Decision Processes, vol. 90, no. 2, pp. 209-224, 2003.

[32] R. M. Holmes, P. Bromiley, C. E. Devers, T. R. Holcomb, and J. B. McGuire, "Management theory applications of prospect theory: accomplishments, challenges, and opportunities," Journal of Management, vol. 37, no. 4, pp. 1069-1107, 2011.

[33] Y. Rosokha and K. Younge, "Motivating innovation: the effect of loss aversion on the willingness to persist," The Review of Economics and Statistics, vol. 102, no. 3, pp. 569-582, 2020.

[34] C. Paraschiv and A. Shyti, Entrepreneurs under Ambiguity: A Prospect Theory Perspective, Entrepreneurship and Behavioral Strategy, Information Age Publishing, Scottsdale, AZ, USA, 2020.

[35] R. D. Gupta, "Risk-attitudes of the NSE 500 firms-Bowman's paradox and prospect theory perspectives," IIMB Management Review, vol. 29, no. 2, pp. 76-89, 2017.

[36] M. D. Mumford, C. Blair, L. Dailey, L. E. Leritz, and H. K. Osburn, "Errors in creative thought? Cognitive biases in a complex processing activity," The Journal of Creative Behavior, vol. 40, no. 2, pp. 75-109, 2006.

[37] D. Kliger and I. Tsur, "Prospect theory and risk-seeking behavior by troubled firms," Journal of Behavioral Finance, vol. 12, no. 2, pp. 29-40, 2011.

[38] F. B. I. Situmeang, G. Gemser, N. M. Wijnberg, and M. A. Leenders, "Risk-taking behavior of technology firms: the role of performance feedback in the video game industry," Technovation, vol. 54, no. 8, pp. 22-34, 2016.

[39] N. Barberis and M. Huang, "Stocks as lotteries: the implications of probability weighting for security prices," American Economic Review, vol. 98, no. 5, pp. 2066-2100, 2008.

[40] N. Su, X. Zhu, and Y. Xin, "Using improved prospect theory to develop a partner selection method for virtual enterprises with unknown weight," Mathematical Problems in Engineering, vol. 2020, Article ID 9608704, 16 pages, 2020.

[41] J. Gu, Y. Zheng, X. Tian, and Z. Xu, "A decision-making framework based on prospect theory with probabilistic linguistic term sets," Journal of the Operational Research Society, vol. 1, no. 1, pp. 1-10, 2020.

[42] K. Stearns, "Failing to fail: the effect of cognitive biases on investment in innovation," Academy of Management Proceedings, vol. 2019, no. 1, Article ID 14189, 2019.

[43] A. Tversky and D. Kahneman, "Advances in prospect theory: cumulative representation of uncertainty," Journal of Risk and Uncertainty, vol. 5, no. 4, pp. 297-323, 1992.

[44] U. Sonnemann, C. F. Camerer, C. R. Fox, and T. Lange, "How psychological framing affects economic market prices in the lab and field," Proceedings of the National Academy of Sciences, vol. 110, no. 29, pp. 11779-11784, 2013.

[45] A. Tversky and D. Kahneman, "Prospect theory: an analysis of decision under risk," Econometrica, vol. 47, no. 2, pp. 263-291, 1979.

[46] P. Bordalo, N. Gennaioli, and A. Shleifer, "Salience in experimental tests of the endowment effect," American Economic Review, vol. 102, no. 3, pp. 47-52, 2012.

[47] X. Zhou, L. Wang, H. Liao, S. Wang, B. Lev, and H. Fujita, “A prospect theory-based group decision approach considering consensus for portfolio selection with hesitant fuzzy information," Knowledge-Based Systems, vol. 168, no. 3, pp. 28-38, 2019.

[48] P. Bordalo, N. Gennaioli, and A. Shleifer, "Salience and asset prices," American Economic Review, vol. 103, no. 3, pp. 623-628, 2013.

[49] A. Zillante, D. C. Read, and M. J. Seiler, "Using prospect theory to better understand the impact of uncertainty on real estate negotiations," Journal of Real Estate Research, vol. 41, no. 1, pp. 75-105, 2019.

[50] F. Desmoulins-Lebeault, L. Meunier, and S. Ohadi, "Does implied volatility pricing follow the tenets of prospect theory?" Journal of Behavioral Finance, vol. 21, no. 2, pp. 157-173, 2020.

[51] C. T. Liao, "Laggards imitate, leaders innovate: the heterogeneous productivity effect of imitation versus innovation," Industrial and Corporate Change, vol. 29, no. 2, pp. 375-394, 2020.

[52] M. Li, B. Nguyen, X. Yu, and Y. Han, "Competition vs. collaboration: a four set game theory-innovation, collaboration, imitation, and "do nothing"' International Journal of Technology Management, vol. 76, no. 3-4, pp. 285-315, 2018.

[53] Y. Su and T. Li, "Simulation analysis of knowledge transfer in a knowledge alliance based on a circular surface radiator model," Complexity, vol. 2020, Article ID 4301489, 27 pages, 2020.

[54] R. M. Samaniego, "Knowledge spillovers and intellectual property rights," International Journal of Industrial Organization, vol. 31, no. 1, pp. 50-63, 2013.

[55] J. P. H. Fan, S. L. Gillan, and X. Yu, "Innovation or imitation?" Journal of Multinational Financial Management, vol. 23, no. 3, pp. 208-234, 2013.

[56] J. Zhou, W. Zhou, T. Chu, Y.-X. Chang, and M.-J. Huang, "Bifurcation, intermittent chaos and multi-stability in a twostage Cournot game with R\&D spillover and product differentiation," Applied Mathematics and Computation, vol. 341, no. 1, pp. 358-378, 2019.

[57] O. Slivko and B. Theilen, "Innovation or imitation? The effect of spillovers and competitive pressure on firms' R\&D strategy choice," Journal of Economics, vol. 112, no. 3, pp. 253-282, 2014.

[58] C. Aspremont and A. Jacquemin, "Cooperative and noncooperative R\&D in duopoly with spillovers," American Economic Review, vol. 78, no. 5, pp. 1133-1137, 1988.

[59] V. Zikos, "R\&D collaboration networks in mixed oligopoly," Southern Economic Journal, vol. 77, no. 1, pp. 189-212, 2010.

[60] Y. Zhang, "When should firms choose a risky new technology? An oligopolistic analysis," Economic Modelling, vol. 91, no. 9, pp. 687-693, 2020.

[61] A. Dubovik and M. C. W. Janssen, "Oligopolistic competition in price and quality," Games and Economic Behavior, vol. 75, no. 1, pp. 120-138, 2012. 
[62] F. J. Xie and J. Shi, "The evolution of price competition game on complex networks," Complexity, vol. 2018, Article ID 9649863, 13 pages, 2018.

[63] R. G. Holcomb, "Product differentiation and economic progress," Quarterly Journal of Austrian Economics, vol. 12, no. 1, p. 17, 2009.

[64] A. Vasile, C. E. Costea, and T. G. Viciu, "An evolutionary game theory approach to market competition and cooperation," Advances in Complex Systems, vol. 15, no. 1, Article ID 1250044, 2012.

[65] O. Bode and F. Ferreira, "Patent licensing: Stackelberg versus Cournot models," Discontinuity and Complexity in Nonlinear Physical Systems, pp. 409-420, Springer, Cham, Switzerland, 2014.

[66] L. A. Julien, "A note on Stackelberg competition," Journal of Economics, vol. 103, no. 2, pp. 171-187, 2011.

[67] K. Žigić, "Intellectual property rights violations and spillovers in North-South trade," European Economic Review, vol. 42, no. 9, pp. 1779-1799, 1998.

[68] L. Yang and K. E. Maskus, "Intellectual property rights, technology transfer and exports in developing countries," Journal of Development Economics, vol. 90, no. 2, pp. 231-236, 2009.

[69] A. Mukherjee, "Social efficiency of entry with market leaders," Journal of Economics \& Management Strategy, vol. 21, no. 2, pp. 431-444, 2012.

[70] S. Dhami, The Foundations of Behavioral Economic Analysis, Oxford University Press, Oxford, UK, 2016.

[71] H. Tamura, "Behavioral models of decision making under risk and/or uncertainty with application to public sectors," Annual Reviews in Control, vol. 32, no. 1, pp. 99-106, 2008.

[72] J. M. Harrison and N. Sunar, "Investment timing with incomplete information and multiple means of learning," $O p$ erations Research, vol. 63, no. 2, pp. 442-457, 2015. 